\title{
Interpretation of Modified Glucose Tolerance Test among Pregnant Malaysian Women
}

\author{
Muna Kh. Al-kubaisi ${ }^{1}$, Saad M. Al-Shibli ${ }^{* 2}$, Nilar Win ${ }^{1}$ \\ ${ }^{1}$ Department of Obstetrics and Gynaecology, College of Medicine, International Islamic University \\ Malaysia Medical Centre \\ ${ }^{2}$ Department of Basic Medical sciences, College of Medicine, International Islamic University Malaysia \\ *Corresponding author: Asst. Prof. Dr. Saad M. Al-Shibli; salshibili2004@yahoo.com
}

Received 04 July 2020;

Accepted 02 August 2020;

Published 14 August 2020

\begin{abstract}
Aim: Is to find the mean and two standard deviation of the serum blood sugar among pregnant women while running the modified oral glucose tolerance test (MOGTT) as screening for gestational diabetes mellitus (GDM) \& to compare the readings with other protocols adopted in diagnosing GDM. Method: A cross sectional study among pregnant women running routine MOGTT at 24-28 weeks' gestation. A total of 149 women participated in 4 months period. The test included $5 \mathrm{ml}$ of venous blood sample taken after fasting for 8 hours and a second blood sample 2 hours after having $200 \mathrm{ml}$ of $75 \mathrm{~g}$ glucose solution within 10 minutes. Results: The mean for the fasting blood sugar is $4.32 \mathrm{mmol} / \mathrm{L} \pm 0.52$ making value of $2 \mathrm{SD}$ of $5.36 \mathrm{mmol} / \mathrm{l}$. The mean of the 2 hours glucose level was $6.11 \mathrm{mmol} / \mathrm{l} \pm 1.38 \mathrm{making}$ the $2 \mathrm{SD}$ value of $8.87 \mathrm{mmol} / \mathrm{l}$. Conclusion: Our results for the 1st reading in MOGTT is near to the value of the local protocol in diagnosing GDM. The 2 hours postprandial reading in the local protocol is fairly low when compared with our findings \& with guidelines of nearby communities.
\end{abstract}

Keywords: MOGTT, GDM, screening protocol, pregnancy, Malaysia.

\section{Introduction}

Gestational diabetes Mellitus (GDM) is a common complication of pregnancy. It is generally known as glucose intolerance that is first detected during pregnancy resulting in hyperglycaemia ${ }^{[1]}$, which causes complications in $10 \%$ of pregnancies ${ }^{[2,3]}$. Among hyperglycaemic cases in pregnancies; the majority is GDM but some have overt diabetes Mellitus (DM) or pre-existing type 1 or type 2 DM. ${ }^{[4]}$.

Gestational diabetes are associated with a wide spectrum of complications that affects the mother and the foetus. Associated complications include macrosomia, polyhydramnios, intrauterine death, increase obstetrical interventions as induction of labour, increase in instrumental deliveries, shoulder dystocia, caesarean section, and much more ${ }^{[5]}$.

Diagnosing GDM is still a subject of controversy; there are no universal trusted reference values for the diagnosis. The cut off values depend basically on the O'Sallivan and Mahan study. O'sullivan took the 2-standard deviation (SD) above the mean for 752 pregnant women in their late 2 nd and early 3rd trimesters (fasting: $5.00 \mathrm{mmol} / \mathrm{L}, 2 \mathrm{~h}: 8.1 \mathrm{mmol} / \mathrm{L}$ ). The value was validated by 20 years follow up and he concluded that $20 \%$ of women will develop diabetes within the first 8 years and $50 \%$ within 20 years [6]. The blood samples that had been used were venous whole blood, this was the case until 1982 were Carpenter made a new study using the plasma to analyse blood glucose by the enzymatic method, this method is still in use today ${ }^{[7]}$. The results of the study were higher than O'sullivan's readings (fasting: $5.27 \mathrm{mmol} / \mathrm{L}, 2 \mathrm{~h}$ : $8.61 \mathrm{mmol} / \mathrm{L}$ ). The International Association of Diabetes in Pregnancy Study Group recommended a new strategy for identifying gestational diabetes in $2010^{[8]}$. This depends on Hyperglycaemia and Adverse Pregnancy Outcome study which is validated by the perinatal outcome, it recommended $5.1 \mathrm{mmol} / \mathrm{L}$ for fasting and 8.5 for $2 \mathrm{~h}$ after $75 \mathrm{~g}$ oral glucose ${ }^{[8]}$. The American Congress of Obstetrician and Gynaecologist reported its own guidelines in GDM ${ }^{[9]}$ and the Canadian diabetes association had done its own work too ${ }^{[10]}$. This variation might reflect a wide range of guidelines adopted by different entities. Taking in consideration previous variation among different recommendations throughout the world, the WHO (2013) recommendation for diagnosing gestational diabetes includes a wide range in the reference values for diagnosis, a fasting plasma glucose of 5.1$6.9 \mathrm{mmol} / \mathrm{L}$, one hour after $75 \mathrm{~g}$ glucose $\geq 10 \mathrm{mmol} / \mathrm{L}$ and two hours of $8.5-11 \mathrm{mmol} / \mathrm{L}^{[11]}$. The recent Malaysian guidelines adopted the fasting blood sugar value from the Hyperglycemia and Adverse Pregnancy Outcome (HAPO) study ${ }^{[12]}$ but maintaining the 2 hours $75 \mathrm{mg}$ value from previous guideline. The guidelines came up with a fasting blood glucose of $5.1 \mathrm{mmol} / \mathrm{L}$ and two hours postprandial (2HPP) of $75 \mathrm{~g}$ glucose of more than $7.8 \mathrm{mmol} / \mathrm{L}$ as criteria of diagnosing GDM ${ }^{[13]}$.

An important factor to be taken into account is the racial difference ${ }^{[14,15,16]}$ in which the values that could be meaningful in one community might not fit other communities. Racial differences were noticed with lipid profile in some studies in Malaysia, the 
same difference might exist for blood sugar ${ }^{[17]}$. It is mandatory for each community to get an idea about the best values to be adopted in their population.

In general, medical institutes began to adopt the 2-SD of the blood sugar readings in a survey study to nominate the blood sugar level as abnormal along with following up their cases for future possibility of developing overt diabetes. The studies in recent advances are evaluating the pregnancy outcome to amend the old cut-off points. A multicentre study may mask the bias of racial differences. It is more convenient to run a national study that is more compatible to each community sharing race, nutritional habits, and attitudes. Such studies can increase the sensitivity of the screening test for GDM and avoid over diagnosis with unnecessary follow-ups, or under diagnosing with increasing complications.

The criteria used to diagnose GDM influences its prevalence, based on systematic review, the prevalence of GDM is $10.6 \%{ }^{[18]}$. Similar prevalence of GDM is observed in South East Asian (1 in 10 women) ${ }^{[19]}$. Prevalence in United State is $7.6 \%$, Europe is $5.4 \%^{[20,21]}$. Until today, there is no universal criteria to diagnose gestational diabetes due to many confounders like environmental, racial, genetic differences, and nutritional habit. Diagnostic criteria need to be tailored for each community, as it is the case with modified foetal growth charts ${ }^{[22]}$.

Over diagnosis of GDM leads to an increased burden to the health care system in term of workload and rate of induction of labour (IOL), CS and health costs, along with increasing anxiety, cost of follow up, and cost of home monitoring on patients.

Screening programs should be sensitive, specific, cost effective, easy, safe, and with a clear policy for diagnosis and treatment ${ }^{[23]}$. Although there are many screening programs for diabetes adopted by medical institutions, the 2 readings (fasting/ 2 hours postprandial) glucose tolerance is still the most widely used $[24,25]$.

\section{Objective}

The objective of the study is to find the mean and the two standard deviations in Malaysian population while running the screening for gestational diabetes by using the modified oral glucose tolerance test (MOGTT).

\section{Materials and Methods}

A cross sectional study was done at primary care centre clinic, at which women were counselled about acceptance for participation in the study. All women with risk factor/s for developing GDM ran a routine modified glucose tolerance (MOGTT) at 24-28 weeks gestation. Women with no risk factors were counselled also to run the test for the sample to represent the real community not only the risk group and for the benefit of randomisation. All women attending the clinic in 4 months period were counselled to participate in the study with a total of 149 women. Patients with diabetes mellitus were not included in the study population as it is unethical to run the test on them. This exclusion might affect our readings. However, the prevalence of overt diabetes at the reproductive age is $2.4 \%^{[26]}$.

After getting consents, their demographic data were obtained and screening for gestational diabetes was done by using MOGTT. The test included $5 \mathrm{ml}$ of venous blood sample taken after fasting for 8 hours and a second blood sample 2 hours after having $200 \mathrm{ml}$ of $75 \mathrm{~g}$ glucose solution within 10 minutes. Patients were instructed not to eat, drink, or perform heavy exercise between the two samples. The data was analysed by using the
SPSS v.23 by obtaining the normal distribution curve for both readings to get the mean blood sugar for the fasting period (FBS) and the 2 hours postprandial ( $2 \mathrm{hpp}$ ). The two standard deviation was obtained using the same system. Descriptive values obtained for the demographic data presented by the mean and standard deviation as well. The 2 tailed Pearson correlations were applied to obtain the significance between different variables.

\section{Results}

Table 1 shows the mean and standard deviation of the different variables in our studied population. The average weight gain was $9.99 \mathrm{Kg} \pm \mathrm{SD}=4.28$.

Table 1: Demographic measures for the studied sample

\begin{tabular}{|l|l|l|}
\hline Variables & Mean & SD \\
\hline Age $($ Years $)$ & 27.59 & 4.13 \\
\hline BMI at booking $(\mathrm{Kg} / \mathrm{m} 2)$ & 24.55 & 5.41 \\
\hline BMI at term $(\mathrm{Kg} / \mathrm{m} 2)$ & 28.5 & 5.11 \\
\hline $\mathrm{Hb}(\mathrm{g} / \mathrm{dl})$ & 11.63 & 1.05 \\
\hline FBS $(\mathrm{mmol} / \mathrm{l})$ & 4.32 & 0.52 \\
\hline $2 \mathrm{hPP}(\mathrm{mmol} / \mathrm{l})$ & 6.11 & 1.38 \\
\hline Baby weight $(\mathrm{Kg})$ & 3.09 & 0.48 \\
\hline
\end{tabular}

Both FBS 1 and 2hpp showed a normal distribution curve (Figure no. 1, no. 2). The mean for the fasting blood sugar is 4.32 $\mathrm{mmol} / \mathrm{L} \pm 0.52$ making value of $2 \mathrm{SD}$ of $5.36 \mathrm{mmol} / \mathrm{L}$. The mean of the 2 hours glucose level was $6.11 \mathrm{mmol} / 1 \pm 1.38$ making the $2 \mathrm{SD}$ value of $8.87 \mathrm{mmol} / \mathrm{L}$.

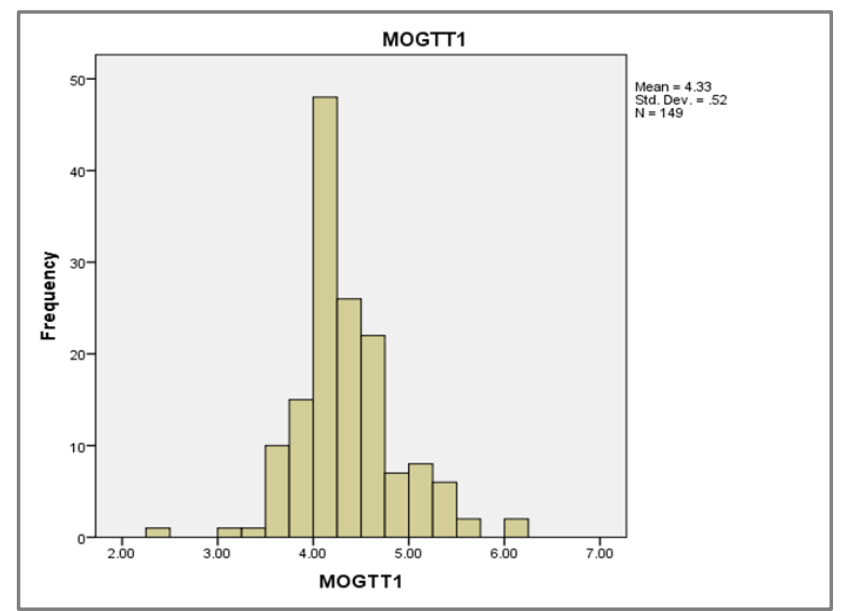

Figure 1: Normal distribution curve of the fasting blood sugar.

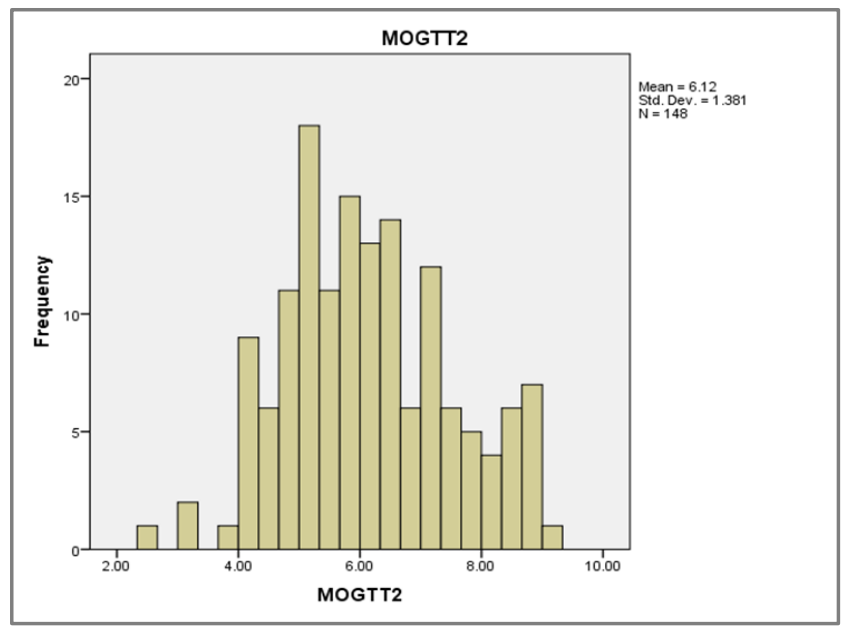

Figure 2: Normal distribution curve of the two hours postprandial blood sugar readings. 
Table 2: Incidence of GDM in the studied sample according to different diagnostic guidelines

\begin{tabular}{|l|l|l|l|}
\hline & $\begin{array}{l}\text { Fasting in } \\
\mathrm{mmol} / \mathrm{L}\end{array}$ & $\begin{array}{l}2 \mathrm{hpp} \mathrm{in} \\
\mathrm{mmol} / \mathrm{L}\end{array}$ & $\begin{array}{l}\text { Incidence of } \\
\text { GDM }\end{array}$ \\
\hline Mean \pm 2SD & $\geq 5.36$ & $\geq 8.87$ & $6.41 \%$ \\
\hline Malaysia & $\geq 5.1$ & $\geq 7.8$ & $21.14 \%$ \\
\hline $\begin{array}{l}\text { Singapore/ } \\
\text { Australia/China }\end{array}$ & $\geq 5.1$ & $\geq 8.5$ & $18.46 \%$ \\
\hline Canadian & $\geq 5.3$ & $\geq 9$ & $7.38 \%$ \\
\hline UK & $\geq 5.6$ & $\geq 7.8$ & $14.09 \%$ \\
\hline
\end{tabular}

Table 2 shows the incidence of GDM when it is calculated using different cut-off points according to guidelines.

\section{Discussion}

During our study, we explored our community blood sugar values while doing routine screening in the late second trimester. The fasting blood sugar showed a mean of $4.32 \mathrm{mmol} / \mathrm{l}$ with a SD of 0.52 . The cut-off point according to the mean $+2-\mathrm{SD}=5.36$ $\mathrm{mmol} / \mathrm{l}$. We are considering our cut-off point as $5.43 \mathrm{mmol} / \mathrm{l}$ according to $\mathrm{O}$ 'Sullivan criteria in calculated the abnormal value to diagnose GDM. Most of the previous works and guidelines recommended a fasting reading ranging $5.00-5.80 \mathrm{mmol} / \mathrm{L}$ apart from the world health organization (WHO) which gives a wide range for fasting value, up to $7 \mathrm{mmol} / \mathrm{L}^{[7,9,11,12,27]}$. Malaysian guidelines recommended fasting blood sugar of $\geq 5.1 \mathrm{mmol} / \mathrm{l}$. This reading is lower than the mean $+2 \mathrm{SD}$ of the population calculated value ${ }^{[13]}$. It might over diagnose but somehow increases the sensitivity of the test in view of high prevalence of GDM in South East Asia ${ }^{[18]}$.

Fasting plasma glucose level decreases by $0.5 \mathrm{mmol} / \mathrm{L}$ by the late first trimester and the early second trimester. It remains static in the second trimester and declines again in third. Diagnostic test using FBS that is done in early pregnancy would over-diagnose GDM $^{[28]}$. Researchers suggested to use higher cut-off point for FBS 6.1-6.9 mmol/L in first trimester to diagnose GDM, taking into account the physiological changes in pregnancy ${ }^{[29]}$. This point of view was suggested as some women with risk factors to develop GDM could benefit from the early diagnostic test. The earlier the foetus is exposed to hyperglycaemia (during organogenesis), the more severe the consequences ${ }^{[30]}$. However, FBS $\geq 5.1 \mathrm{mmol} / \mathrm{L}$ is generally accepted as hyperglycaemia in pregnancy regardless of trimesters ${ }^{[12]}$.

Postprandial levels are usually higher in pregnant women as compared to the non-pregnant ${ }^{[31]}$. The $2 \mathrm{hpp}$ blood sugar level showed a mean of $6.11 \mathrm{mmol} / \mathrm{L}$ with a SD of 1.38 . The cut-off point for the $2 \mathrm{hpp}$ according to the mean $+2-\mathrm{SD}=8.87 \mathrm{mmol} / \mathrm{L}$. We are considering our cut-off point as $8.87 \mathrm{mmol} / \mathrm{L}$ according to O'Sullivan criteria in calculated the abnormal value to diagnose GDM. The range of two hours postprandial in most references is between $8-9 \mathrm{mmol} / \mathrm{L}$ apart from WHO \& UK, which gives a value, as low as $7.8 \mathrm{mmol} / \mathrm{L}^{[11,12,18,32]}$. Our reading for the $2 \mathrm{hpp}$ reflects a harmony with other guidelines that adopt two hours postprandial glucose reading between $8-9 \mathrm{mmol} / \mathrm{L}$.

Malaysian guidelines is following the WHO criteria of 7.8 $\mathrm{mmol} / \mathrm{L}$ for the 2 hours reading in diagnosing GDM. It is considered the lowest among the guidelines if compared with other countries in the same geographical area ${ }^{[29,33]}$. To modulate this value, we need to run further studies exploring the complications associated with adopting higher reference numbers as cut-off point; This would decrease the cost and burden on patients \& medical institutions in case we are over diagnosing GDM.
Table 2 shows the incidence of GDM in our studied population using the criteria of different guidelines ${ }^{[10,13,32,34,35,36]}$. A wide spectrum of incidence ranges from $6-21 \%$ can be noticed in table 2. We think; it is difficult to establish a universal cut off point for MOGTT test values. This might be explained by the existence of different confounders like genetic, racial, dietary habits...etc. Test should be tailored on each region or community that is sharing the same environment, which include the race, life style dietary habits.

In our study, the incidence of GDM is $6.04 \%$ while it is $21.14 \%$ according to the Malaysian guidelines in the studied population. We think that; this difference is due to the fact that Malaysian guideline has adopted international cut off point in diagnosing GDM rather than a community-based study. We recommend a larger community survey covering whole Malaysia for more accurate results keeping in view to keep reasonable sensitivity of our tests.

\section{Conclusion}

In our studied community; the mean $+2 \mathrm{SD}$ of fasting blood sugar during MOGTT is $5.36 \mathrm{mmol} / \mathrm{L}$, which is near to the values adopted by many nearby countries. However, our 2 hpp value which is $8.87 \mathrm{mmol} / \mathrm{L}$ which is considered as high compared to other universal guidelines.

\section{Study Limitation}

The sample size are relatively small for a community survey study.

\section{Precise}

The purpose of the study is to compare the blood sugar reading of the MOGTT and its compatibility with the regional protocols.

\section{Acknowledgement}

We would like to show our gratitude to the patients who accept to participate in the study on voluntary bases. We also would like to thank all supporting staffs who help in making this work achievable.

\section{References}

[1] Baz, B., Riveline, J. P., \& Gautier, J. F. (2016). Gestational diabetes mellitus: definition, aetiological and clinical aspects. Eur J Endocrinol, 174(2), R43-51.

[2] DeSisto, C. L., Kim, S. Y., \& Sharma, A. J. (2014). Peer reviewed: Prevalence estimates of gestational diabetes mellitus in the United States, pregnancy risk assessment monitoring system (prams), 2007-2010. Preventing chronic disease, 11.

[3] Melchior, H., Kurch-Bek, D., \& Mund, M. (2017). The prevalence of gestational diabetes: a population-based analysis of a nationwide screening program. Deutsches Ärzteblatt International, 114(24), 412.

[4] Wang, C., \& Yang, H. X. (2016). Diagnosis, prevention and management of gestational diabetes mellitus. Chronic diseases and translational medicine, 2(4), 199.

[5] Mitanchez, D. (2010). Foetal and neonatal complications in gestational diabetes: perinatal mortality, congenital malformations, macrosomia, shoulder dystocia, birth 
injuries, neonatal complications. Diabetes \& metabolism, 36(6 Pt 2), 617-627.

[6] O'Sullivan, J. B., Mahan, C. M., Charles, D., \& Dandrow, R. V. (1973). Screening criteria for high-risk gestational diabetic patients. American journal of obstetrics and gynecology, 116(7), 895-900.

[7] Carpenter, M. W., \& Coustan, D. R. (1982). Criteria for screening tests for gestational diabetes. American journal of obstetrics and gynecology, 144(7), 768-773.

[8] International Association of Diabetes and Pregnancy Study Groups Consensus Panel. (2010). International association of diabetes and pregnancy study groups recommendations on the diagnosis and classification of hyperglycemia in pregnancy. Diabetes care, 33(3), 676682. 2010;33(3):676-682, 2010.

[9] ACOG, "Gestational diabetes mellitus ACOG guideline," ACOG practice bulletin; no. 137, p. 11, Aug 2013.

[10] David Thompson, Howard Berger, Denice Feig, et al, Canadian Diabetes Association Clinical Practice Guidelines Pregnancy, 291 2014. Available: http://www.cmnrp.ca/uploads/documents/Dr_Richard_T homas_Handouts.pdf.

[11] World Health Organization. (2013). Diagnostic criteria and classification of hyperglycaemia first detected in pregnancy (No. WHO/NMH/MND/13.2). World Health Organization.

[12] Coustan, D. R., Lowe, L. P., Metzger, B. E., \& Dyer, A. R. (2010). The Hyperglycemia and Adverse Pregnancy Outcome (HAPO) study: paving the way for new diagnostic criteria for gestational diabetes mellitus. American journal of obstetrics and gynecology, 202(6), 654-e1.

[13] MOH, "Clinical Practice Guidline; Managment of Diabetes in Pregnancy.," Minestry of Health Malaysia, Kuala Lumpur, 2017.

[14] Trivedi, A. N., Grebla, R. C., Wright, S. M., \& Washington, D. L. (2011). Despite improved quality of care in the Veterans Affairs health system, racial disparity persists for important clinical outcomes. Health Affairs, 30(4), 707-715.

[15] Herman, W. H. (2016). Are there clinical implications of racial differences in $\mathrm{HbA1c}$ ? Yes, to not consider can do great harm!. Diabetes Care, 39(8), 1458-1461.

[16] Ziemer, D. C., Kolm, P., Weintraub, W. S., Vaccarino, V., Rhee, M. K., Twombly, J. G., ... \& Phillips, L. S. (2010). Glucose-independent, black-white differences in hemoglobin A1c levels: a cross-sectional analysis of 2 studies. Annals of internal medicine, 152(12), 770-777.

[17] Cheah, W. L., Chang, C. T., Hazmi, H., \& Wan Muda, W. M. (2016). Gender and racial differences in the cardiovascular risk factors among overweight and obese rural adults, Kuching and Samarahan division, Sarawak, Malaysia. Journal of nutrition and metabolism, 2016.

[18] Behboudi-Gandevani, S., Amiri, M., Yarandi, R. B., \& Tehrani, F. R. (2019). The impact of diagnostic criteria for gestational diabetes on its prevalence: a systematic review and meta-analysis. Diabetology \& metabolic syndrome, 11(1), 11.

[19] Nguyen, C. L., Pham, N. M., Binns, C. W., Duong, D. V., \& Lee, A. H. (2018). Prevalence of gestational diabetes mellitus in eastern and south eastern Asia: a systematic review and meta-analysis. Journal of diabetes research, 2018
[20] Casagrande, S. S., Linder, B., \& Cowie, C. C. (2018). Prevalence of gestational diabetes and subsequent type 2 diabetes among US women. Diabetes research and clinical practice, 141, 200-208

[21] Eades, C. E., Cameron, D. M., \& Evans, J. M. (2017). Prevalence of gestational diabetes mellitus in Europe: a meta-analysis. Diabetes research and clinical practice, 129, 173-181.

[22] Kiserud, T., Benachi, A., Hecher, K., Perez, R. G., Carvalho, J., Piaggio, G., \& Platt, L. D. (2018). The World Health Organization fetal growth charts: concept, findings, interpretation, and application. American journal of obstetrics and gynecology, 218(2), S619-S629.

[23] Dobrow, M. J., Hagens, V., Chafe, R., Sullivan, T., \& Rabeneck, L. (2018). Consolidated principles for screening based on a systematic review and consensus process. Cmaj, 190(14), E422-E429.

[24] Östlund, I., \& Hanson, U. (2003). Occurrence of gestational diabetes mellitus and the value of different screening indicators for the oral glucose tolerance test. Acta obstetricia et gynecologica Scandinavica, 82(2), 103-108.

[25] Saeedi, M., Hanson, U., \& Fadl, H. (2017). Evaluation of screening methods for Gestational diabetes mellitus in Sweden. In 49th Annual Meeting of the Diabetic Pregnancy Study Group (EASD), Nyborg, Denmark, September 7-10, 2017 (pp. 79-80).

[26] Yuan, H., Li, X., Wan, G., Sun, L., Zhu, X., Che, F., \& Yang, Z. (2017). Type 2 diabetes epidemic in East Asia: a 35-year systematic trend analysis. Oncotarget, 9(6), 6718-6727. https://doi.org/10.18632/oncotarget.22961

[27] Canadian Diabetes Association Clinical Practice Guidelines Expert Committee. (2003). clinical practice guidelines for the prevention and management of diabetes in Canada. Canadian Diabetes Association. Can J Diabetes, 27(Suppl 2), S10-3.

[28] Geurtsen, M. L., van Soest, E. E., Voerman, E., Steegers, E. A., Jaddoe, V. W., \& Gaillard, R. (2019). High maternal early-pregnancy blood glucose levels are associated with altered fetal growth and increased risk of adverse birth outcomes. Diabetologia, 62(10), 18801890.

[29] Zhu, W. W., Yang, H. X., Wei, Y. M., Yan, J., Wang, Z. L., Li, X. L., ... \& Zhang, H. (2013). Evaluation of the value of fasting plasma glucose in the first prenatal visit to diagnose gestational diabetes mellitus in China. Diabetes care, 36(3), 586-590.

[30] Zhao, J., Hakvoort, T. B., Willemsen, A. M., Jongejan, A., Sokolovic, M., Bradley, E. J., ... \& Lamers, W. H. (2016). Effect of hyperglycemia on gene expression during early organogenesis in mice. PloS one, 11(7), e0158035.

[31] Angueira, A. R., Ludvik, A. E., Reddy, T. E., Wicksteed, B., Lowe, W. L., \& Layden, B. T. (2015). New insights into gestational glucose metabolism: lessons learned from 21 st century approaches. Diabetes, 64(2), 327-334.

[32] NICE guideline (2015) Diabetes in pregnancy: management from preconception to the postnatal period https://www.nice.org.uk/guidance/ng3/resources/diabetes -in-pregnancy-management-from-preconception-to-thepostnatal-period-51038446021

[33] Juan, J., Yang, H. X., Su, R. N., \& Kapur, A. (2019). Diagnosis of gestational diabetes mellitus in China: 
perspective, progress and prospects. Maternal-Fetal Medicine, 1(1), 31-37.

[34] Queensland Clinical Guidelines (2015): Gestational Diabetes Mellitus. Available at: https://www.health.qld.gov.au/qcg/documents/g-gdm.pdf

[35] Claudia C, Chong Yap Seng, et al. (2018). Gestational diabetes mellitus an update on screening, diagnosis, and follow-up. Appropriate care guideline. Available at: https://www.ace-hta.gov.sg/public-data/our-
guidance/GDM\%20-

$\% 20$ An\%20update\%20on\%20screening,

$\%$ 20diagnosis\%20and\%20follow-

up\%20(May\%202018).pdf. Published 20 May 2018.

[36] Wei-wei Zhu, MD, Hui-xia Yang, MD, Diagnosis of Gestational Diabetes Mellitus in China, Diabetes Care 2013 Jun; 36(6): e76-e76.https://doi.org/10.2337/dc122624 